\title{
Prevalence of psychiatric symptoms among refugee adolescents in Turkey: a controlled study
}

\author{
Mehmet Karadag, ${ }^{1}$ iD Hakan Ogutlu' ${ }^{2}$ (i) \\ ${ }^{1}$ Child and Adolescent Department, Medical School, Gaziantep University, Gaziantep, Turkey. ${ }^{2}$ Child and Adolescent Psychiatry Department, \\ Ankara City Hospital, Ankara, Turkey.
}

\begin{abstract}
Objective: To investigate prevalence of internalized and externalized psychological symptoms and war-related adverse events among a representative secondary-school sample of Syrian refugee adolescents, and to compare levels of depression, anxiety, and stress between Syrian refugee adolescents and Turkish adolescents.

Methods: Syrian refugee adolescents $(n=70)$ and Turkish adolescents $(n=70)$ were asked to complete the Depression, Anxiety, and Stress Scales (DASS-42) and Strengths and Difficulties Questionnaire (SDQ).

Results: DASS and SDQ scores were significantly different between the two groups; scores in all problem areas were higher in refugees. Loss of a family member increased depression, stress, and total difficulty scored, whereas witnessing death increased anxiety and stress and experiencing multiple events increased depression, anxiety, and total difficulty scores. Maternal years of schooling correlated inversely with SDQ emotional symptoms, conduct problems, and hyperactivity/inattention problem scores. Both parents' years of schooling correlated inversely with SDQ total difficulties scores.

Conclusion: Syrian refugee adolescents had higher depression, anxiety, behavioral problems, peer relationship problems, and general difficulties than their Turkish peers. Facilitating refugees' access to mental health services, educating their parents, consulting, and monitoring at-risk children may contribute to reducing psychosocial problems in refugee children.
\end{abstract}

Keywords: Adolescent; refugee; psychology; anxiety; depression

\section{Introduction}

The Syrian civil war broke out in 2011, causing one of the most significant migrations in world history. The clashes of arms that began between the regime forces and the opponents devastated many lives. Millions fled the country to survive the war; approximately 21.3 million people were displaced. ${ }^{1}$

Turkey hosts the highest number of Syrian refugees circa 3.5 million, according to data from the United Nations High Commissioner for Refugees (UNHCR). ${ }^{2}$ Syrian refugees who previously lived in refugee camps and temporary shelters and maintained an isolated life in Turkey have recently begun to integrate into various of Turkey's social systems. Many projects and programs were organized for this purpose, including the Sinhat Project, AFAD Refugee Centers, Project on Supporting the Integration of Syrian Children into the Turkish Education System, etc. ${ }^{3}$

Despite these efforts to integrate into Turkish society, traumatic memories related to the war, sociocultural

Correspondence: Mehmet Karadag, Department of Child and Adolescent Psychiatry, Medical School, Gaziantep University, Gaziantep, Turkey.

E-mail: karadagm @ gantep.edu.tr

Submitted Feb 18 2020, accepted Apr 03 2020, Epub Jul 172020. adaptation problems, economic problems, and other difficulties of forced migration make these children and adolescents more vulnerable in terms of psychiatric disorders. ${ }^{4}$ Indeed, most research into this topic has shown that refugee children and adolescents experience more severe behavioral and emotional problems. ${ }^{5-8}$ Besides, depressive disorders, anxiety disorders, and posttraumatic stress disorder (PTSD) are more common in refugee children and adolescents. ${ }^{9}$

Adolescence is a period in which the prevalence of psychopathologies increases. ${ }^{10}$ As early diagnosis and treatment can change the course of psychiatric disorders, evidence from studies conducted in this age range is essential. ${ }^{11}$

To the best of our knowledge, there have been no studies in Turkey that provide an estimate of the prevalence of psychiatric symptoms among Syrian refugee adolescents and their Turkish counterparts. Thus, we aimed to investigate the prevalence of internalized and externalized psychological symptoms and war-related adverse events among a representative secondary school

How to cite this article: Karadag M, Ogutlu $\mathrm{H}$. Prevalence of psychiatric symptoms among refugee adolescents in Turkey: a controlled study. Braz J Psychiatry. 2021;43:55-60. http://dx.doi.org/ 10.1590/1516-4446-2020-0916 
sample of Syrian refugee adolescents. We hypothesized that levels of these symptoms would be higher among refugee adolescents than among their Turkish peers at the same school.

\section{Methods}

\section{Participants}

The data presented in this cross-sectional study were collected at a school in Mardin, a city at Turkey's border with Northern Syria. The school had a total of 350 students. This representative school was chosen from a district where Syrian refugees live. The study was conducted in April 2019. All Syrian adolescents enrolled in this school were included in the study, and host-country adolescents were matched with refugee adolescents for age and sex. Students were then selected randomly from the student lists, which were in alphabetical order. According to these criteria, we first included 70 Syrian adolescents and 70 Turkish adolescents. After excluding adolescents who did not have literacy in Turkish, 62 Syrians and 66 Turks were included in the study.

\section{Procedure}

We used the Depression, Anxiety, and Stress Scales (DASS-42) and the Strengths and Difficulties Questionnaire (SDQ), both of which can be used in Turkish and Arabic. Also, we used specific forms to collect sociodemographic data and information on war-related traumatic experiences. Questions included: "Did you lose any family members in the war?," "Did you witness the death of a family member or a close friend?," "Was a family member or a close friend ever abducted or taken hostage?," "Did you witness or experience torture or violence during the war?," "Did you experience or witness serious injuries or accidents?," and "Did you witness (see or hear) any explosion?."

\section{Materials}

The DASS-42 questionnaire, which has validity and reliability in both Turkish and Arab populations, ${ }^{12,13}$ was used to compare depression, anxiety, and stress levels of adolescents. DASS-42 is a self-response questionnaire consisting of 42 questions, which can quantify all three negative emotional states as normal, mild, moderate, severe, and extremely severe. This questionnaire can be used from 12 years of age. ${ }^{14}$

The Turkish and Arabic versions of the SDQ were also both shown to be valid and reliable questionnaires. ${ }^{15,16}$ The SDQ consists of 25 questions and subheadings such as attention deficiency and hyperactivity symptoms, behavior problems, emotional problems, peer problems, and social behavior problems.

\section{Statistics}

Statistical analyses were performed in SPSS version 23.0. The assumption of normal distribution was examined using the Kolmogorov-Smirnov test. Mann-Whitney $U$ and Student $t$ tests were used to compare the scale scores among the Syrian refugee and Turkish groups and other categorical variables. Chi-square and Fisher's exact tests were used to compare the nominal variables. Spearman correlation analysis was used to test for correlations of quantitative data. Statistical significance was accepted at $p \leqslant 0.05$.

\section{Ethics statement}

We received approval from the regional ethics committee and educational authorities for this research.

\section{Results}

The mean age of the participants was $13.42 \pm 0.96$ years (range, 12-16). The mean age of the refugee group was $13.66 \pm 1.12$ years, and the mean age of the control group was $13.20 \pm 0.79$ years. The gender distribution of the sample was $50.8 \%(n=65)$ male and $49.2 \%$ female. There was no significant difference between the two gender groups $(p=0.016)$.

When the refugee and control groups were compared, there was no significant difference in terms of previous psychiatric admission; antidepressant use; marital status of the parents (married, divorced, or deceased); family arrangement (nuclear or extended); mother's work status, total years of education received, and history of psychiatric disorder; or father's work status and history of psychiatric disorder. However, paternal education attainment in years of schooling was higher in the control group $(p=0.022)$.

Table 1 shows the DASS and SDQ scale scores of the Syrian refugee group and the Turkish group. DASS depression, anxiety, and stress scores and SDQ emotional symptoms, conduct problems, peer relationship problems, and total difficulties scores were significantly different between the two groups, always higher in Syrian refugees. SDQ hyperactivity/inattention and prosocial behaviors scores did not differ significantly between the two groups.

The ratio of adolescents receiving normative scores as quantified by DASS was significantly higher in the Turkish group $(58.7 \%$ for DASS depression, $43.6 \%$ for anxiety, $51.5 \%$ for stress) when compared to the refugee group (16.9\% for DASS depression, $20 \%$ for anxiety, $27.4 \%$ for stress). Likewise, moderate and severe emotional states as quantified by the DASS were significantly overrepresented among the Syrian refugee group when compared to their Turkish peers. Table 2 shows all ratios of groups quantified according to the DASS scale. In terms of gender, there were no significant differences between DASS/depression, anxiety, stress and SDQ/total difficulties scores between boys and girls.

The average number of years that refugees had spent in Turkey was $5.08 \pm 1.77$ (95\% confidence interval [95\% Cl] 4.63-5.53). DASS/depression scores of children were found to increase as the number of years spent in Turkey increased $(p=0.037, R=0.265)$. Table 3 shows stressful life events experienced by refugees. Fifty-three percent of 
Table 1 Depression, Anxiety, and Stress Scales (DASS-42) and Strengths and Difficulties Questionnaire (SDQ) scores for refugee and control groups

\begin{tabular}{|c|c|c|c|}
\hline & Refugees & Controls & $p$-value \\
\hline \multicolumn{4}{|l|}{ DASS } \\
\hline Depression & $16.65 \pm 7.69(14.69-18.60)$ & $9.45 \pm 8.36(7.40-11.51)$ & $\leqslant 0.001 *$ \\
\hline Anxiety & $16.55 \pm 7.51(14.64-18.45)$ & $12.30 \pm 7.76(10.40-14.21)$ & $\mathbf{0 . 0 0 2} 2^{\dagger}$ \\
\hline Stress & $19.29 \pm 7.64(17.35-21.23)$ & $14.15 \pm 7.17(12.39-15.91)$ & $\leqslant 0.001 *$ \\
\hline Emotional symptoms & $3.82 \pm 2.29(3.24-4.41)$ & $2.50 \pm 2.10(1.98-3.02)$ & $0.001^{*}$ \\
\hline \multicolumn{4}{|l|}{ SDQ } \\
\hline Conduct problems & $3.45 \pm 2.55(2.80-4.10)$ & $1.94 \pm 1.87(1.48-2.40)$ & $0.001^{*}$ \\
\hline Hyperactivity/inattention & $3.34 \pm 1.64(2.92-3.76)$ & $3.11 \pm 2.24(2.56-3.66)$ & $0.376^{*}$ \\
\hline Peer relationship problems & $3.95 \pm 1.99(3.45-4.46)$ & $3.23 \pm 1.96(3.75-3.71)$ & $0.045^{*}$ \\
\hline Prosocial behaviors & $7.29 \pm 2.02(6.78-7.80)$ & $7.26 \pm 2.67(6.60-7.91)$ & $0.708^{*}$ \\
\hline Total difficulties & $21.85 \pm 6.93(20.09-23.61)$ & $18.05 \pm 5.40(16.72-19.37)$ & $0.001^{\dagger}$ \\
\hline
\end{tabular}

Data presented as mean \pm standard deviation (95\% confidence interval).

Bold type denotes significant between-group differences.

* Mann-Whitney $U$ test.

Student $t$ test.

Table 2 Depression, Anxiety, and Stress Scales (DASS-42) grading for refugee and control groups

\begin{tabular}{lccc}
\hline Scales & Refugees & Controls & p-value \\
\hline DASS & & & \\
Depression & & & \\
$\quad$ Normal & $10(16.9)$ & $37(58.7)$ & $\leqslant \mathbf{0 . 0 0 1}^{*}$ \\
$\quad$ Mild & $11(18.6)$ & $9(14.3)$ & \\
$\quad$ Moderate & $21(35.6)$ & $12(19.0)$ & \\
$\quad$ Severe & $17(28.8)$ & $5(7.9)$ & \\
& & & \\
Anxiety & & & \\
Normal & $8(20.0)$ & $24(43.6)$ & $\mathbf{0 . 0 3 3}^{\dagger}$ \\
Mild & $2(5.0)$ & $6(10.9)$ & \\
Moderate & $12(30.0)$ & $12(21.8)$ & \\
Severe & $18(45.0)$ & $13(23.6)$ & \\
Stress & & & \\
$\quad$ Normal & $17(27.4)$ & $34(51.5)$ & $\mathbf{0 . 0 0 2 *}$ \\
Mild & $6(9.7)$ & $12(18.2)$ & \\
Moderate & $28(45.2)$ & $17(25.8)$ & \\
Severe & $11(17.7)$ & $3(4.5)$ & \\
\hline
\end{tabular}

Data presented as $\mathrm{n}(\%)$.

Bold type denotes significant between-group differences.

* Chi-square test.

${ }^{\dagger}$ Fisher's exact test.

refugees were exposed to the loss of a family member, $47 \%$ of them witnessed death, $27 \%$ were kidnapped or taken hostage, $16 \%$ were tortured or exposed to violence, $26 \%$ were exposed to severe injury or accidents, $55 \%$ witnessed an explosion, and $65 \%$ were exposed to multiple events.

DASS/depression, stress and SDQ/total difficulties scores of those who lost a family members, DASS/ anxiety and stress scores of those who witnessed death, and DASS/depression, anxiety, stress, and SDQ/total difficulties scores of those who experienced multiple stressful life events were found to be significantly higher than those of participants who had not experienced such events. Table 4 shows comparisons of stressful life events and scores from the scales.

When the correlations between DASS and SDQ scores and parents' educational attainment received were examined, the mother's years of schooling was inversely

\begin{tabular}{|c|c|}
\hline Negative events & $\mathrm{n}(\%)$ \\
\hline \multicolumn{2}{|c|}{ Loss of a family member } \\
\hline Yes & $33(53)$ \\
\hline No & $29(47)$ \\
\hline \multicolumn{2}{|l|}{ Witness to death } \\
\hline Yes & $29(47)$ \\
\hline No & $33(53)$ \\
\hline \multicolumn{2}{|c|}{ Kidnapping or taken as a hostage } \\
\hline Yes & $17(27)$ \\
\hline No & $45(73)$ \\
\hline \multicolumn{2}{|c|}{ Torture or violence } \\
\hline Yes & $10(16)$ \\
\hline No & $52(84)$ \\
\hline \multicolumn{2}{|c|}{ Serious injury or accident } \\
\hline Yes & $16(26)$ \\
\hline No & $46(74)$ \\
\hline \multicolumn{2}{|c|}{ Witness the explosion } \\
\hline Yes & $34(55)$ \\
\hline No & $28(45)$ \\
\hline \multicolumn{2}{|c|}{ Experiencing multiple events } \\
\hline Yes & $40(65)$ \\
\hline No & $22(36)$ \\
\hline
\end{tabular}

correlated with SDQ emotional symptoms, conduct problems, and hyperactivity/inattention problem scores. Both parents' years of schooling correlated inversely with SDQ/total difficulties scores. Table 5 shows the correlations between years of schooling of refugee parents and DASS and SDQ scale scores.

\section{Discussion}

Syrian refugees have been migrating to Turkey since 2011, and many have now lived in Turkey for nearly eight years. Despite this long period, refugee children in our study had higher levels of depression, anxiety, stress 
Table 4 Comparison of negative events with Depression, Anxiety, and Stress Scales (DASS-42)/depression, DASS/anxiety, DASS/stress and Strengths and Difficulties Questionnaire (SDQ)/total difficulties scores

\begin{tabular}{|c|c|c|c|c|c|c|c|c|c|c|c|c|}
\hline \multirow[b]{3}{*}{ Negative events } & \multicolumn{9}{|c|}{ DASS } & \multirow{2}{*}{\multicolumn{3}{|c|}{$\begin{array}{c}\text { SDQ } \\
\text { Total difficulties } \\
\end{array}$}} \\
\hline & \multicolumn{3}{|c|}{ Depression } & \multicolumn{3}{|c|}{ Anxiety } & \multicolumn{3}{|c|}{ Stress } & & & \\
\hline & $\mathrm{n}$ & SD & $\mathrm{p}$-value & $\mathrm{n}$ & SD & $\mathrm{p}$-value & $\mathrm{n}$ & SD & $\mathrm{p}$-value & $\mathrm{n}$ & SD & $\mathrm{p}$-value \\
\hline \multicolumn{13}{|c|}{ Loss of a family member } \\
\hline Yes & 19.03 & 6.59 & \multirow[t]{2}{*}{$0.008 *$} & 18.24 & 6.88 & \multirow[t]{2}{*}{$0.057^{*}$} & 21.45 & 7.53 & \multirow[t]{2}{*}{$0.019^{\dagger}$} & 25.64 & 5.38 & \multirow[t]{2}{*}{$\leqslant 0.001 *$} \\
\hline No & 13.93 & 8.04 & & 14.62 & 7.83 & & 16.83 & 7.11 & & 17.55 & 5.96 & \\
\hline \multicolumn{13}{|l|}{ Witness to death } \\
\hline Yes & 18.41 & 7.30 & \multirow[t]{2}{*}{$0.090 *$} & 19.66 & 6.49 & \multirow[t]{2}{*}{$0.002^{*}$} & 21.41 & 7.42 & \multirow[t]{2}{*}{$0.043^{\dagger}$} & 23.66 & 7.05 & \multirow[t]{2}{*}{$0.054^{*}$} \\
\hline No & 15.09 & 7.79 & & 13.82 & 7.36 & & 17.42 & 7.44 & & 20.27 & 6.53 & \\
\hline \multicolumn{13}{|c|}{ Kidnapping or taken as a hostage } \\
\hline Yes & 16.88 & 6.33 & \multirow[t]{2}{*}{$0.883 *$} & 16.94 & 7.20 & \multirow[t]{2}{*}{$0.802^{*}$} & 18.47 & 8.57 & \multirow[t]{2}{*}{$0.564^{\dagger}$} & 22.41 & 6.26 & \multirow[t]{2}{*}{$0.701 *$} \\
\hline No & 16.56 & 8.20 & & 16.40 & 7.69 & & 19.60 & 7.34 & & 21.64 & 7.22 & \\
\hline \multicolumn{13}{|c|}{ Torture or violence } \\
\hline Yes & 14.90 & 6.03 & \multirow[t]{2}{*}{$0.438 *$} & 15.70 & 7.36 & \multirow[t]{2}{*}{$0.700^{*}$} & 18.90 & 7.02 & \multirow[t]{2}{*}{$0.605^{\dagger}$} & 21.30 & 6.20 & \multirow[t]{2}{*}{$0.785^{*}$} \\
\hline No & 16.98 & 7.97 & & 16.71 & 7.59 & & 19.37 & 7.82 & & 21.96 & 7.11 & \\
\hline \multicolumn{13}{|c|}{ Serious injury or accident } \\
\hline Yes & 15.06 & 5.70 & \multirow[t]{2}{*}{$0.343^{*}$} & 15.25 & 6.86 & \multirow[t]{2}{*}{$0.426^{*}$} & 18.88 & 7.68 & \multirow[t]{2}{*}{$0.784^{\dagger}$} & 21.69 & 5.46 & \multirow[t]{2}{*}{$0.912^{*}$} \\
\hline No & 17.20 & 8.25 & & 17.00 & 7.74 & & 19.43 & 7.71 & & 21.91 & 7.43 & \\
\hline Witness the expl & & & & & & & & & & & & \\
\hline Yes & 16.82 & 6.57 & $0.847^{*}$ & 16.47 & 6.75 & $0.929 *$ & 20.00 & 6.92 & $0.411^{\dagger}$ & 22.35 & 5.65 & $0.552 *$ \\
\hline No & 16.43 & 8.98 & & 16.64 & 8.46 & & 18.43 & 8.49 & & 21.25 & 8.30 & \\
\hline Experiencing mu & & & & & & & & & & & & \\
\hline Yes & 18.38 & 6.71 & $0.016 *$ & 17.95 & 6.82 & $0.047^{*}$ & 21.23 & 6.94 & $0.014^{\dagger}$ & 24.32 & 6.12 & $\leqslant 0.001^{*}$ \\
\hline No & 13.50 & 8.48 & & 14.00 & 8.17 & & 15.77 & 7.75 & & 17.36 & 6.10 & \\
\hline
\end{tabular}

$\mathrm{SD}=$ standard deviation.

Bold type denotes significant differences.

* Student $t$ test.

'Mann-Whitney $U$ test.

Table 5 Correlations between education years of refugees' parents and Depression, Anxiety, and Stress Scales (DASS-42) and Strengths and Difficulties Questionnaire (SDQ) scores

\begin{tabular}{|c|c|c|c|c|}
\hline \multirow[b]{2}{*}{ Scales } & \multicolumn{2}{|c|}{ Mother's years of schooling } & \multicolumn{2}{|c|}{ Father's years of schooling } \\
\hline & rho & $p$-value & rho & $\mathrm{p}$-value \\
\hline \multicolumn{5}{|l|}{ DASS } \\
\hline Depression & -0.247 & 0.053 & -0.125 & 0.335 \\
\hline Anxiety & -0.120 & 0.353 & -0.056 & 0.668 \\
\hline Stress & -0.135 & 0.294 & 0.064 & 0.623 \\
\hline \multicolumn{5}{|l|}{ SDQ } \\
\hline Emotional symptoms & $-0.277^{*}$ & 0.029 & -0.132 & 0.31 \\
\hline Conduct problems & $-0.337^{*}$ & 0.007 & -0.228 & 0.077 \\
\hline Hyperactivity/inattention & $-0.383 *$ & 0.002 & -0.098 & 0.454 \\
\hline Peer relationship problems & -0.169 & 0.19 & -0.123 & 0.345 \\
\hline Prosocial behaviors & 0.124 & 0.338 & -0.216 & 0.095 \\
\hline Total difficulties & $-0.327^{*}$ & 0.01 & $-0.252^{*}$ & 0.05 \\
\hline
\end{tabular}

Bold type denotes significant differences.

* Spearman correlation analysis. The correlations were significant at $p \leqslant 0.05$.

levels, behavioral problems, peer relationship problems, and general difficulties than their Turkish peers.

In a study evaluating hospital admissions of Syrian children, scores of depression, generalized anxiety disorder, and PTSD were found to be higher in Syrian children. $^{5,17}$ Similar results were found in our study, and depression, anxiety, and stress scores were significantly higher in Syrian adolescents when compared to Turkish adolescents attending the same school.
In the Syrian refugee group, moderate or severe depression scores, as quantified by the DASS, accounted for $63 \%$ of the group, anxiety scores for $75 \%$ of the group, and stress scores for $62 \%$ of the group. Also, in other studies on Syrian refugees in Turkey, anxiety, depression, and stress scores were found to be higher in immigrant children. In the Bahçessehir school study conducted on Syrian refugee children staying in the Islahiye Refugee Camp, Gaziantep, in $2012-2013$, 44\% of the children were 
found to be suffering from depression and $45 \%$ from PTSD. ${ }^{18}$ In another study on Syrian refugee children in Temporary Education Centers in Istanbul, Turkey, $69 \%$ of the participants had high anxiety scores and $44.2 \%$ had high posttraumatic stress scores. ${ }^{19}$ In a school sample of Syrian refugee children in Şanlıurfa, Turkey, $47.9 \%$ had high depression scores and $53.2 \%$ had high anxiety scores. ${ }^{20}$ The rates of anxiety, depression, and PTSD obtained in the present study were higher than those found in previous investigations. This may be explained by the narrower age range of our sample (12 to 16 years), whereas in other studies the age range was wider. Due to the higher prevalence of psychopathology in adolescents than in children in the general population, the rates we determined may be higher than those in other studies involving refugee children. ${ }^{10}$

Syrian refugee adolescents also had more peer relationship problems than their Turkish counterparts. Similar results have been obtained in refugee studies in Australia and the United Kingdom. ${ }^{21,22}$ This higher incidence of peer relationship issues may be due to refugee children discontinuing education, having difficulties in language learning, not being able to achieve sociocultural harmony, and experiencing psychological distress.

Conversely, no difference was found between the two groups in terms of prosocial behavior and attention deficithyperactivity, as quantified by the SDQ. Social behaviors, such as helping, sharing, conforming, and cooperating in society, ensure that bonds are formed and maintained in a healthy manner between individuals. Prosocial behaviors enable the individual to establish and maintain social relations, and have been shown to contribute to psychosocial adjustment in war-affected children. ${ }^{23}$ Although the Syrian refugee group in our study had similar prosocial scores than the Turkish group, their higher scores of psychiatric disorders suggest that these prosocial behaviors did not have a protective effect, probably due to the impact of war and migration-related difficulties. Attentiondeficit/hyperactivity disorder did not differ between the two groups, possibly due to its strong genetic and neurodevelopmental components. ${ }^{24}$

In our study, we found that, as maternal educational attainment increased, emotional symptoms, behavior problems, and attention-deficit/hyperactivity symptom scores of their children decreased, while as the years of schooling of both parents increased, total difficulties score decreased. In a study conducted by Yayan \& Düken, ${ }^{25}$ the children of refugee parents with high educational level, economic condition, and sociocultural status in Turkey had lower levels of PTSD, anxiety, and depression than peers with less-educated and less well-off parents. Our study also showed that a higher education level of mothers contributed significantly to a decrease in the development of psychiatric symptoms in their children. In the Young Middle Eastern Refugees' Mental Health Study in Denmark, lower maternal education was shown to lead to both internalization and externalization problems. ${ }^{26}$ Another possible explanation for this relationship may be that families with low educational level may have a lower income and socioeconomic status, and their children may accordingly have a decrease in psychological resilience and, thus, a predisposition to psychopathologies.
As seen in the Bahçeşehir study ${ }^{18}$ and in previous work by Gormez et al., ${ }^{19}$ the Syrian refugees in our study were exposed to a high rate of traumatic experiences, including the loss of a family member, witnessing a death, being kidnapped or taken hostage, torture, violence, serious injury, accident, or explosion, with many experiencing multiple events. In our sample, loss of a family member was shown to increase depression, stress, and total difficulty scores; witnessing a death increased anxiety and stress; and experiencing multiple events increased depression, anxiety, stress, and total difficulty scores. In the Gormez et al. study, ${ }^{19}$ loss of a family member was shown to be associated with PTSD and anxiety, while torture or violence were associated with anxiety. It was a striking finding that traumas involving death, such as loss of a family member or witnessing death, were more debilitating than kidnapping or being taken hostage, being exposed to torture, violence, serious injury, accident, or explosion. In a study conducted with refugees in London, the association of loss of a family member with high PTSD scores showed that death had a more traumatic effect on children than separation from family members. In addition, as determined in our study, the death of family members was one of the most critical consequences of war and migration for children's psychological health. ${ }^{27}$ Another important finding to consider is that experiencing multiple events was associated with an increase in all problem scores.

Refugee children who migrated to Turkey earlier were found to have higher depression scores. The first cause of this finding could be that children who migrate earlier will be more susceptible to developing psychopathology. In a study conducted with refugee children in Canada, the rate of development of psychopathology was shown to decrease as the age of the child increased. ${ }^{28}$ In another Canadian study, the development of mood disorders and anxiety disorders decreased with increasing age for refugees. ${ }^{29}$ The second possible cause may be the relationship with length of stay. In a study conducted in Denmark, psychopathology scores decreased in refugees after staying in the host country for 8-9 years. ${ }^{30}$ Thus, staying in the host country for an average of 5 years may be too short a time to adapt. The third possible cause is that children who migrated earlier were older and might have had higher rates of psychopathology due to older age. $^{10}$

The major limitations in our study were our inability to determine the income and socioeconomic status of the families, the lack of information about traumatic experiences in the control group, the lack of a scale for PTSD, and the limited number of participants.

In conclusion, refugee adolescents had higher depression, anxiety, stress, behavioral problems, peer relationship problems, and general difficulties than their Turkish peers, as quantified by the DASS and the SDQ. These children have experienced many traumatic events and have high levels of anxiety, depression, and stress. As maternal educational attainment increased, emotional symptoms and behavioral problems in the adolescents decreased, and as the education level of both parents increased, the total difficulties score decreased. Loss of a 
family member, witnessing death, and multiple traumatic experiences contributed to the development of psychopathology in the refugee adolescents.

Facilitating refugees' access to mental health services, enhancing educational opportunities for their parents, counseling and monitoring at-risk children who have witnessed death or a family member's loss, and providing social activities, peer support, and teacher assistance may contribute to reducing the psychosocial problems of refugee children. There is a need for further intervention programs to address these issues.

\section{Acknowledgements}

We would like to thank the authorities who granted permission for this study and all the participants who attended.

\section{Disclosure}

The authors report no conflicts of interest.

\section{References}

1 United Nations High Commissioner for Refugees. Syria regional refugee response. Total persons of concern by country of asylum [Internet]. [cited 2020 Jun 15]. data2.unhcr.org/en/situations/syria

2 United Nations High Commissioner for Refugees. Syria regional refugee response. Registered Syrian refugees [Internet]. [cited 2020 Jun 15]. data2.unhcr.org/en/situations/syria/location/113

3 Turkey's Disaster and Emergency Management Authority (AFAD). Turkey response to Syria crisis [Internet]. 2017 Jun [cited 2020 Jun 15]. reliefweb.int/sites/reliefweb.int/files/resources/wfp279438.pdf

4 Beiser M, Dion R, Gotowiec A, Hyman I, Vu N. Immigrant and refugee children in Canada. Can J Psychiatry. 1995;40:67-72.

5 Yayan EH, Düken ME, Özdemir AA, Celebioğlu A. Mental health problems of Syrian refugee children: post-traumatic stress, depression and anxiety. J Pediatr Nurs. 2020;51:e27-32.

6 Leavey G, Hollins K, King M, Barnes J, Papadopoulos C, Grayson K. Psychological disorder amongst refugee and migrant schoolchildren in London. Soc Psychiatry Psychiatr Epidemiol. 2004;39:191-5.

7 Khamis V. Posttraumatic stress disorder and emotion dysregulation among Syrian refugee children and adolescents resettled in Lebanon and Jordan. Child Abuse Negl. 2019;89:29-39.

8 Medeiros GC, Sampaio D, Sampaio S, Lotufo-Neto F. Mental health of refugees: report of a successful case in Brazil. Braz J Psychiatry. 2014;36:274-5.

9 Jabbar SA, Zaza HI. Post-traumatic stress and depression (PSTD) and general anxiety among Iraqi refugee children: a case study from Jordan. Early Child Dev Care. 2017;189:1114-34.

10 Roberts RE, Attkisson CC, Rosenblatt A. Prevalence of psychopathology among children and adolescents. Am J Psychiatry. 1998;155: 715-25.

11 Kessler RC, Demler O, Frank RG, Olfson M, Pincus HA, Walters EE, et al. Prevalence and treatment of mental disorders, 1990 to 2003. N Engl J Med. 2005;352:2515-23.
12 Moussa MT, Lovibond P, Laube R, Megahead HA. Psychometric properties of an arabic version of the depression anxiety stress scales (DASS). Res Soc Work Pract. 2017;27:375-86.

13 Bilgel N, Bayram N. Turkish version of the depression anxiety stress scale (DASS-42): psychometric properties. Noro Psikiyatr Ars. 2010;47:118-26.

14 Lovibond S, Lovibond P. Manual for the depression anxiety stress scales. 2nd ed. Sydney: Psychology Foundation; 1995.

15 Güvenir T, Özbek A, Baykara B, Arkar H, Şentürk B, İncekaş S. Güçler ve güçlükler anketi'nin (gga) Türkçe uyarlamasinin psikometrik özellikleri. Çocuk ve Gençlik Ruh Sağliği Dergisi. 2008;15:65-74.

16 Alyahri A, Goodman R. Validation of the arabic strengths and difficulties questionnaire and the development and well-being assessment. East Mediterr Health J. 2006;12 Suppl 2:S138-46.

17 Bustamante LH, Leclerc E, Mari JJ, Brietzke E. It is time to prepare mental health services to attend to migrants and refugees. Braz J Psychiatry. 2016;38:263-4.

18 Özer S, Sirin SR, Oppedal B. Bahçeşehir study of Syrian refugee children in Turkey. İstanbul: Bahçeşehir Üniversitesi; 2016.

19 Gormez V, Kılıç HN, Orengul AC, Demir MN, Demirlikan S, Demirbaş $\mathrm{S}$, et al. Psychopathology and associated risk factors among forcibly displaced Syrian children and adolescents. J Immigr Minor Health. 2018;20:529-35.

20 Kandemir H, Karatas H, Ceri V, Solmaz F, Kandemir SB, Solmaz A Prevalence of war-related adverse events, depression and anxiety among Syrian refugee children settled in Turkey. Eur Child Adolesc Psychiatry. 2018;27:1513-7.

21 Hanes G, Sung L, Mutch R, Cherian S. Adversity and resilience amongst resettling Western Australian paediatric refugees. J Paediatr Child Health. 2017;53:882-8.

22 Fazel M, Doll H, Stein A. A school-based mental health intervention for refugee children: an exploratory study. Clin Child Psychol Psychiatry. 2009;14:297-309.

23 Betancourt TS, Borisova II, Williams TP, Brennan RT, Whitfield TH, de la Soudiere M, et al. Sierra Leone's former child soldiers: a followup study of psychosocial adjustment and community reintegration. Child Dev. 2010;81:1077-95.

24 Palladino VS, McNeill R, Reif A, Kittel-Schneider S. Genetic risk factors and gene-environment interactions in adult and childhood attention-deficit/hyperactivity disorder. Psychiatr Genet. 2019;29: 63-78.

25 Yayan EH, Düken ME. Determination of psychosocial conditions of refugee children living in society. Perspect Psychiatr Care. 2019;55: 644-51.

26 Montgomery E. Long-term effects of organized violence on young Middle Eastern refugees' mental health. Soc Sci Med. 2008;67: 1596-603.

27 Heptinstall E, Sethna V, Taylor E. PTSD and depression in refugee children: associations with pre-migration trauma and post-migration stress. Eur Child Adolesc Psychiatry. 2004;13:373-80.

28 Tousignant M, Habimana E, Biron C, Malo C, Sidoli-LeBlanc E, Bendris N. The Quebec adolescent refugee project: psychopathology and family variables in a sample from 35 nations. J Am Acad Child Adolesc Psychiatry. 1999;38:1426-32.

29 Patterson B, Kyu HH, Georgiades K. Age at immigration to Canada and the occurrence of mood, anxiety, and substance use disorders. Can J Psychiatry. 2013;58:210-7.

30 Montgomery E. Trauma and resilience in young refugees: a 9-year follow-up study. Dev Psychopathol. 2010;22:477-89. 